http://jmscr.igmpublication.org/home/ ISSN (e)-2347-176x ISSN (p) 2455-0450 crossref DOI: https://dx.doi.org/10.18535/jmscr/v8i12.32

\author{
Journal Of Medical Science And Clinical Research \\ IGM Publication \\ An official Publication of IGM Publication
}

\title{
Pattern of traumatic head injury in Makurdi, north central Nigeria: Accident and Emergency experience
}

\author{
Authors \\ Annongu Isaac Terkimbi ${ }^{1}$, Hameed Mohammed ${ }^{1}$, Chia Daniel Msuega ${ }^{1}$ \\ Kator Paul Iorpagher ${ }^{2}$, Nathaniel Ayoughur ${ }^{2}$ \\ ${ }^{1}$ Department of Radiology, College of Health Sciences, Benue State University, Makurdi \\ ${ }^{2}$ Department of Radiology, Benue State University Teaching Hospital Makurdi \\ *Corresponding Author \\ Annongu, Isaac Terkimbi \\ Department of Radiology, College of Health Sciences, Benue State University, Makurdi
}

\begin{abstract}
Traumatic brain injury (TBI) is a common condition presenting in the accident and Emergency Department (AED). Defined as injury to the scalp, skull and brain, no age group is spared. The study aims to highlight the epidemiological pattern associated with head injury patients as seen in the AED of this tertiary institution where the study was carried out. This was a 27 months retrospective study of all head injury patients who met the criteria for traumatic brain injury in the AED. Data was collected from the emergency cards and case notes, then collated and analyzed using the descriptive statistics on SPSS 16, with the $p$ value taken as $<0.05$. One thousand, three hundred and twenty eight (1328) patients were recorded at the AED during the period under review; 123(9.2\%) of them met the inclusion criteria for the study. There were 101 (87.1\%) males and 22 (17.9\%) female. The mean age incidence 33.5 years was in the 31 - 40 year age group. Civil servants constituted the highest occupational group 40 (32.5\%). Most (59.3\%) of the cases resulted from motorcycle (MC) accident; then motor vehicle (MV) $22.0 \%$, assaults $12.2 \%$, fall $8.1 \%$ and domestic injury $2.4 \%$.For severity, $76(61.8 \%)$ of the patients had mild $\mathrm{HI}$, $17.9 \%$ had moderate and $20.3 \%$ had severe HI. $72.4 \%$ were discarded from AED,22.0\% were referred or admitted into the wards. There were 2 deaths all males giving a mortality rate of $1.6 \%$.TBI is a common presentation at AED. Civil servants within the age range 21-40 years were mostly implicated and RTA was the commonest etiology factor especially MCA. Improving the state of our roads, licensing road users and compliance to traffic regulations will go a long way in reducing this menace.
\end{abstract}

Keywords: trauma, brain, injury, aetiology, accident \& emergency.

\section{Introduction}

Head injury (HI) could be defined as damage to the scalp, skull or brain caused by external forces, ${ }^{1}$ it varies from trivial head wounds to traumatic brain injuries (TBIs) ${ }^{2}$
TBI has been divided into two distinct groups: primary and secondary brain injury. The primary injury is the result of the initial mechanical forces, resulting in shearing and compression of neuronal, glial, and vascular tissue whereas the secondary 
injury is described as the consequence of further physiological insults, such as ischaemia, ${ }^{3,4}$ reperfusion and hypoxia, to areas of 'at risk' brain in the period after the initial injury.

TBI has a bimodal incidence distribution; normally, young adult males comprise the largest peak because of motor vehicle accidents and alcohol- associated trauma, ${ }^{5}$ with a second smaller peak in the elderly, consequent to falls.

In Nigeria, an incidence rate of 2710/100,000 per year has been reported in an accident and emergency department (AED). ${ }^{6}$

Depending on the level of consciousness at presentation, TBI could be grouped into mild, if Glasgow Coma Score (GCS) is 13-15, moderate if it is $8-12$ and if GSC is $<8$ it classified as severe. The majority of TBI is classified as mild, and around $8-10 \%$ is classified as moderate or severe. $^{7,8}$ Patients with mild TBI have a good prognosis providing treatable complications are not missed. Overall mortality in this group is around $0.1 \%$ and is associated predominantly with missed intra-cranial haemorrhage. ${ }^{9}$

Approximately $30 \%$ of patients admitted to hospital with GCS score $<13$ will ultimately die; ${ }^{10}$ mortality for those with GCS of $\leq 8$ after resuscitation may be as high as $50 \% .^{11,12}$ Generally, severe TBI, Signs of increased intracranial pressure (ICP) at admission, presence of hyperglycemia, hypoxia, contusion, diffuse axonal injury (DAI), or intracranial bleeding will predicted poor TBI outcome. ${ }^{13}$

Early specialist medical and surgical management of patients with TBI is associated with improved outcome. ${ }^{14,15}$ Prompt and appropriate resuscitation and early management is therefore viewed as an essential part of the supportive care provided for these patients ${ }^{16}$

The study therefore aims to evaluate the common causes, types, presentation, and outcome of TBI in the $\mathrm{A} / \mathrm{E}$ of the tertiary institution in our environment.

\section{Method}

This was a retrospective study of all patients presenting with $\mathrm{HI}$ at the AED of the Benue state
University Teaching Hospital makurdi from January 2018- March 2020. Makurdi which is predominantly a civil servant town is the state capital of Benue state located in the North central Nigeria. People use different means of transportation inter and intra state, mainly motor vehicles (MV) and motorcycles (MC). The state teaching hospital is a tertiary health institution that serves as a referral center for the state and some surrounding States of the country.

Demographic data on age, sex, occupation, educational status, GCS at presentation, mechanism of injury, interval before presentation, and outcome prior to admission into the ward/referral or discharge from the Accident and Emergency Department, were assessed from the $\mathrm{A} / \mathrm{E}$ records department of the hospital.

Except excluded from the study as stated below, all traumatic patients with history and clinical features of TBI were included in the study. Mechanism of injury was classified as caused by MV, MC, falls, assault and domestic injuries. Interval at presentation was grouped into $\leq 24 \mathrm{hrs}$, $>24 \mathrm{hrs}$ but $\leq 1$ week and $>1$ week. The outcome was classified as patient got well and discharged from $\mathrm{A} / \mathrm{E}$, admitted into the wards or referred, died or patient seeks for discharged against medical advice (DAMA). Patients' whose GCS was $\geq 13$ were classified as having mild TBI while those with GCS between 9-12 and $\leq 8$ were classified as moderate and severe TBI respectively.

Even though most of the people in the state have a form of tertiary education, majority are farmers due unavailability of white collar jobs. Others include traders, commercial MC riders popularly called Okada, MV drivers, civil servants, students and preschool children. Those who had formal education were classified as having primary, secondary and tertiary education.

Excluded were Patients whose HI was secondary to haematological causes, cerebrovascular diseases, psychiatric illnesses, or seizures. Also excluded were patients who were certified dead on arrival at $\mathrm{A} / \mathrm{E}$. 
Data were analyzed using SPSS version ----software. Results were presented as frequencies and proportions for categorical data and mean \pm SD for continuous variables, respectively. The chi-squared test was used to compare the proportions of males and females in relation to the variables. $P$ values of 0.05 or less were considered significant.

\section{Results}

During the study period which spans from January 2018 to March 2020, a total of 1328 admissions were made to the $\mathrm{A} / \mathrm{E}$, trauma cases were 289 $(21.7 \%)$ and out of these, $123(9.2 \%)$ patients met the inclusion criteria with head injury for this study. There were 101 males $(87.1 \%)$ and 22 females $(17.9 \%)$ giving a male to female ratio of 4.6:1(fig 1). The ages of the patients ranged from 1-74 years. The highest frequency of $32(26.0 \%)$ was observed in the age range of 21-30 years followed by age range of 31-40 years with 25 (20.3\%). Paediatrics age group of the range $0-10$ years were next with a total number of $20(16.3 \%)$ cases as shown in table 1 .

Patients with tertiary education were surprisingly more affected 53(43.1\%) and were mostly civil servants, Primary and secondary level of education almost shared the same value accounting for $25(20.3 \%)$ and 26(21.1) cases respectively while those with no formal form of education were the least with $19(15.4 \%)$ cases (Fig 2/fig 3).

Motorcycles (MC) was the most common cause of HI, being present in $73(59.3 \%)$ patients. This was followed by motor car accident in (22.0\%), assaults $15(12.2 \%)$, falls $10(8.1 \%)$ and domestic injury in 3(2.4\%) as shown in fig 4.

Similarly Motorcycle was the commonest cause of most HI among all the groups. Age group 21-30 was the highest followed by age group 31-40years and the least was age group 74-80years, however this was statistically insignificant $(\mathrm{p}=0.502)$. MVA has a fair share in all the age groups though slightly higher in the age groups $41-50$ years and 31-40years. Falls were commonest in age group 010years as shown in table 1 .

Also the male sex was the most involved in all the causes of HI but was statistically insignificant $(\mathrm{p}=0.064)$. The highest was by MC [58(57\%)] followed by MVA [18(175) then falls, only in domestic accidents that the females slightly edged the males (table 1).

Sixty one patients $(49.6 \%)$ presented within $24 \mathrm{hrs}$ of accident, $40(32.5 \%)$ within a week and 22(17.9\%) after one week. (Fig 5).

Majority of patients in the study had mild form of HI 76(61.8\%), moderate and severe HI accounted for $22(17.9 \%)$ and $25(20.3 \%)$ respectively (table 1).

Eighty nine (72.4\%) patients were discharged from AED consisting of 71 males and 18 females, the highest frequency of survivors were in the age group 21-30 years. Twenty seven patients $(22.0 \%)$ were referred or admitted into the wards, $2(1.6 \%)$ died all males, in the age groups 0 10 and $71-80$ years. and $5(4.1 \%)$ also all males requested to be discharged against medical advice(fig6/table 1).

Most of the referred or ward admissions came from those with MC HI which shows the highest number with severe forms of head injury [13(52\%)]. The two patient that died in the study were each by MC and MVA and they were all males .Table 1 
Fig 1: Sex Distribution

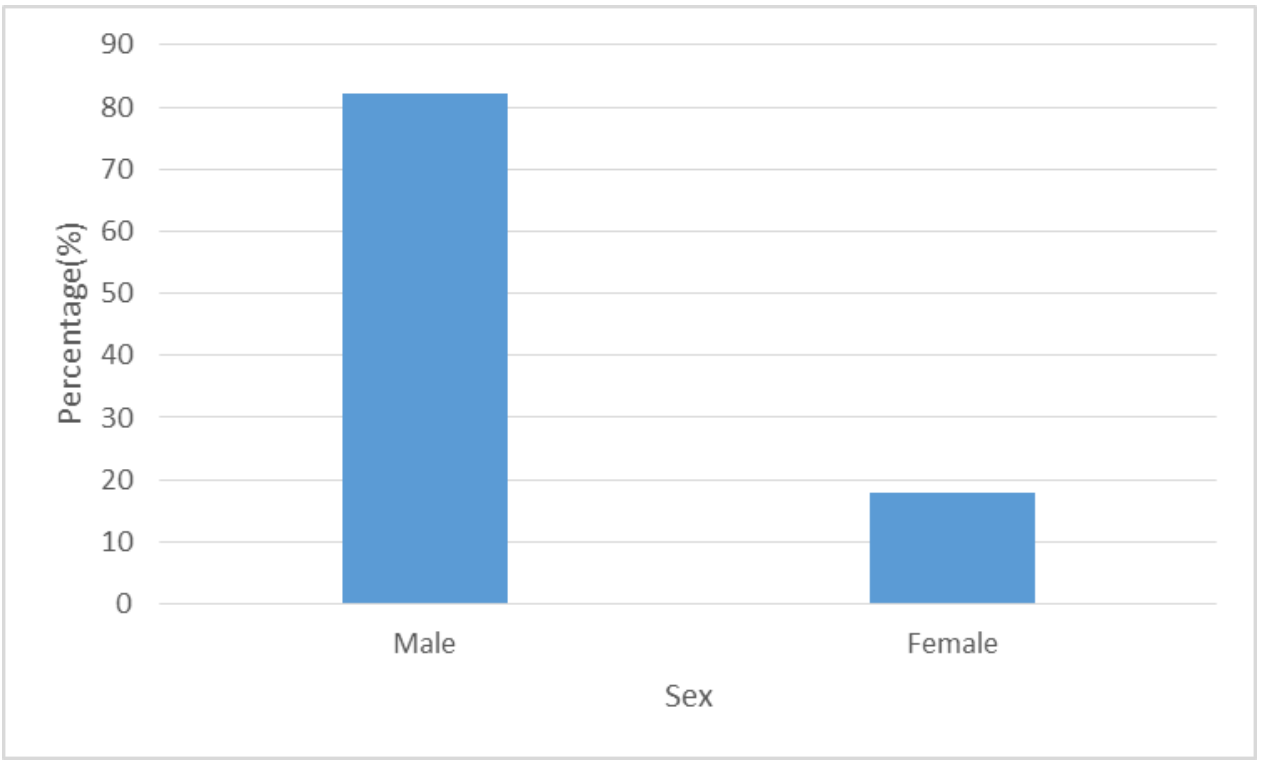

Table 1: Characteristics of traumatic brain injury Sub classification

\begin{tabular}{|c|c|c|c|c|c|c|}
\hline \multirow[t]{2}{*}{ Age } & \multicolumn{4}{|c|}{ Aetiology } & \multirow[b]{2}{*}{ Domestic } & \multirow[b]{2}{*}{ Total } \\
\hline & MC & MVA & Fall & Assault & & \\
\hline $0-10$ & 10 & 3 & 6 & 0 & 1 & 20 \\
\hline $11-20$ & 3 & 3 & 1 & 1 & 0 & 8 \\
\hline $21-30$ & 20 & 3 & 2 & 5 & 2 & 32 \\
\hline $31-40$ & 15 & 4 & 0 & 6 & 0 & 25 \\
\hline $41-50$ & 7 & 5 & 1 & 3 & 0 & 16 \\
\hline $51-60$ & 9 & 2 & 0 & 0 & 0 & 11 \\
\hline $61-70$ & 6 & 1 & 0 & 0 & 0 & 7 \\
\hline $70-80$ & 3 & 1 & 0 & 0 & 0 & 4 \\
\hline Total & 73 & 22 & 10 & 15 & 3 & 123 \\
\hline \multicolumn{7}{|l|}{ Sex } \\
\hline Male & 58 & 18 & 9 & 15 & 1 & 101 \\
\hline Female & 15 & 4 & 1 & 0 & 2 & 22 \\
\hline Total & 73 & 22 & 10 & 15 & 3 & 123 \\
\hline \multicolumn{7}{|l|}{ Severity } \\
\hline Mild & 43 & 12 & 8 & 12 & 1 & 76 \\
\hline Moderate & 17 & 2 & 0 & 2 & 1 & 22 \\
\hline Severe & 13 & 8 & 2 & 1 & 1 & 25 \\
\hline Total & 73 & 22 & 10 & 15 & 3 & 123 \\
\hline \multicolumn{7}{|l|}{ Outcome } \\
\hline Discharged & 53 & 12 & 9 & 13 & 2 & 89 \\
\hline Referred & 16 & 7 & 1 & 2 & 1 & 27 \\
\hline Died & 1 & 1 & 0 & 0 & 0 & 2 \\
\hline DAMA & 3 & 2 & 0 & 0 & 0 & 5 \\
\hline Total & 73 & 22 & 10 & 15 & 3 & 123 \\
\hline
\end{tabular}


Fig.2 Educational status of patients involved in TBI

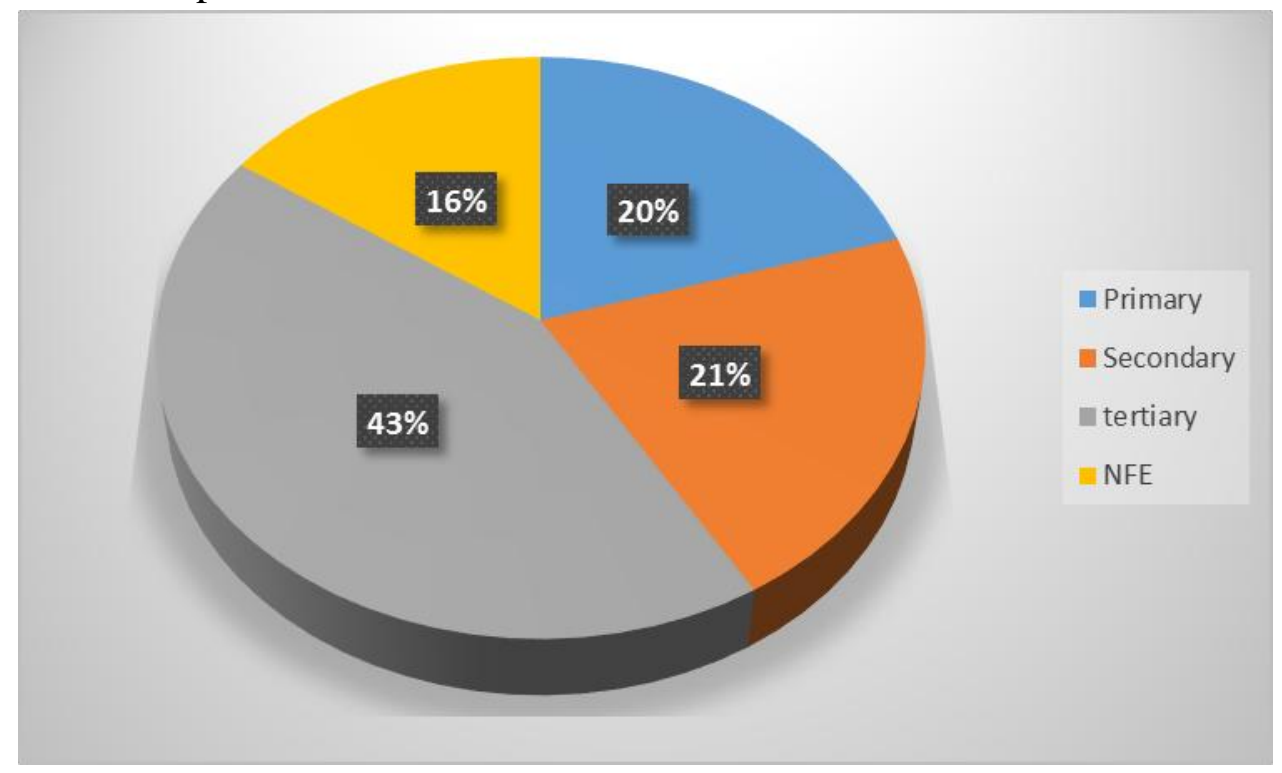

Fig 3: Occupations of victims with TBI

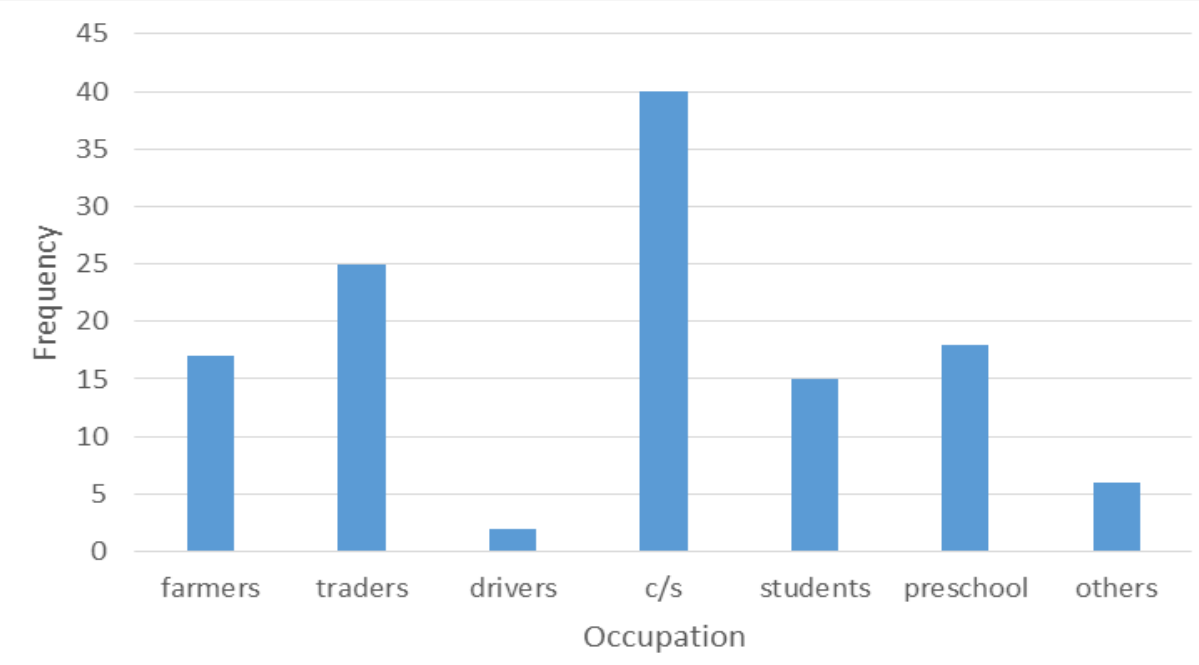

Fig: 4 Common causes of TBI in our environment

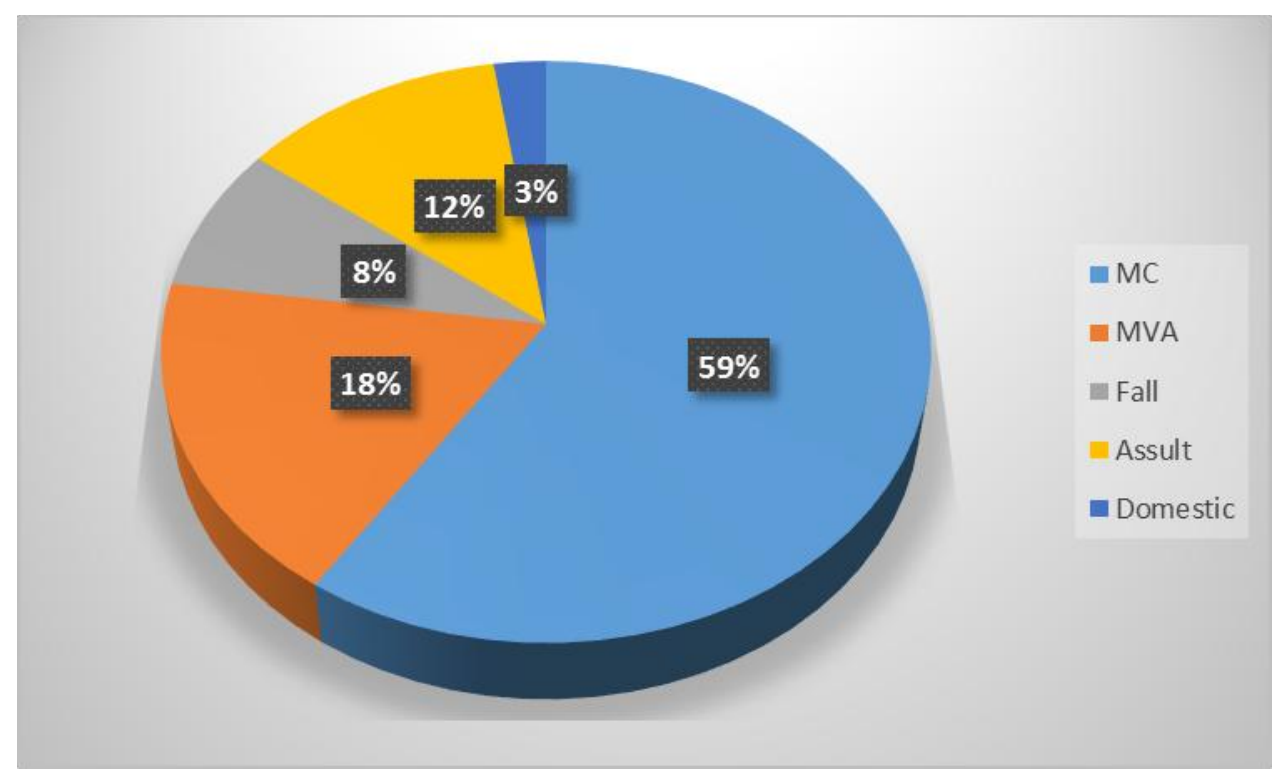




\section{JMSCR Vol||08||Issue||12||Page 193-201||December}

Fig 5: Interval at presentation to $\mathrm{A} / \mathrm{E}$

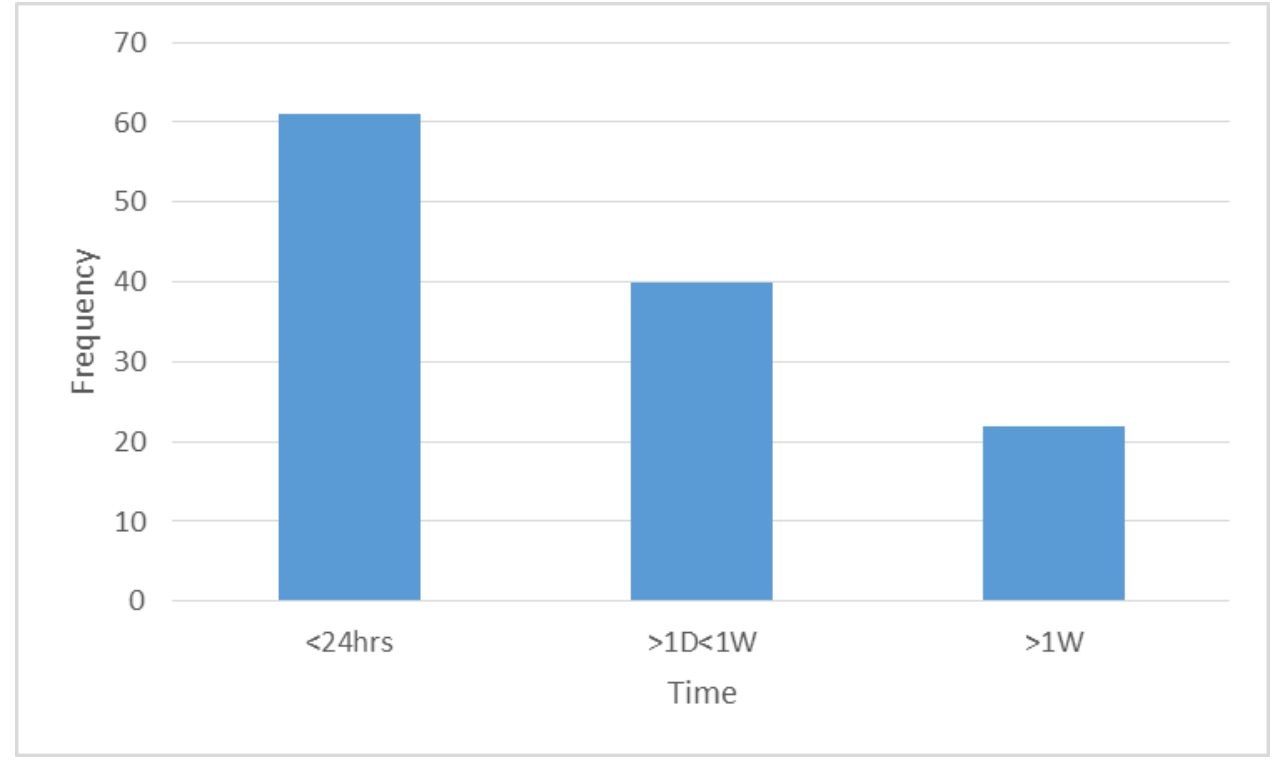

Fig 6: Patients outcome at A/E following TBI

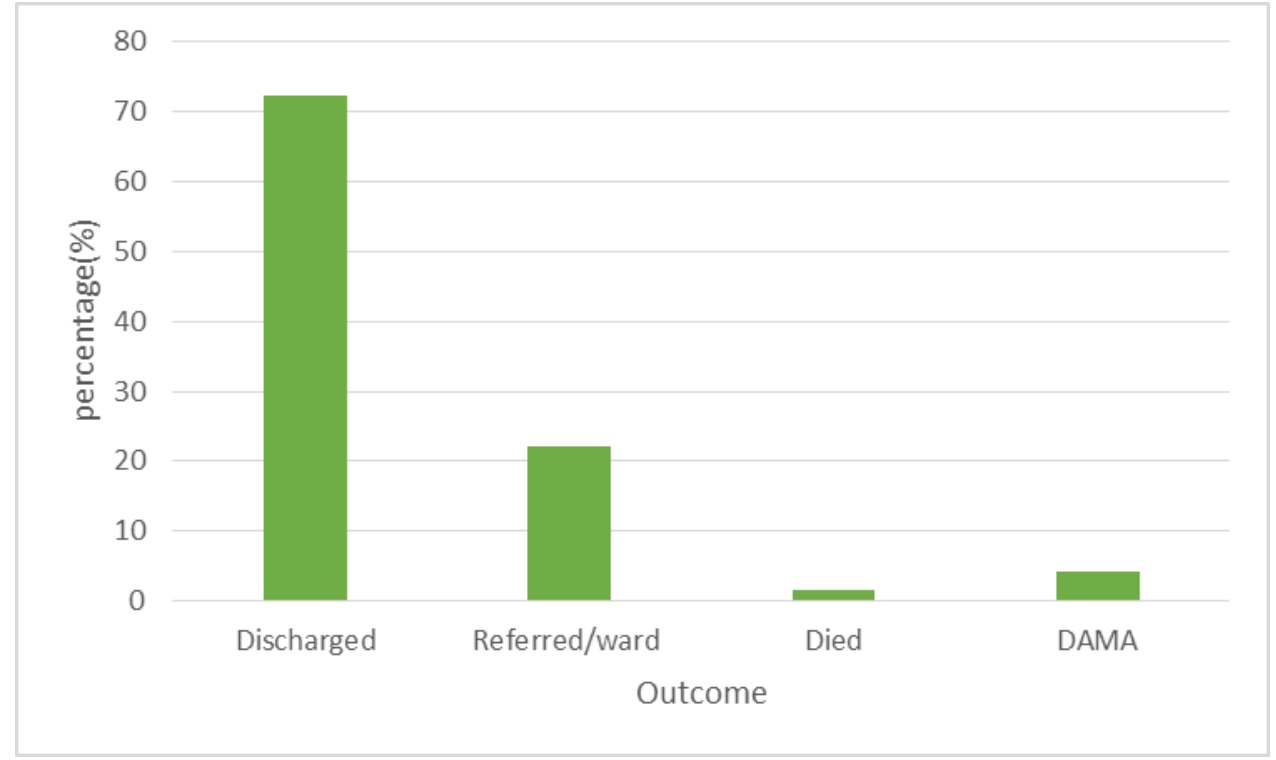

\section{Discussion}

In this study, HI occurred in 9.3\% of all patients with trauma admitted in the AED similar to the findings in other regions. ${ }^{17}$

Males were found to be involved in TBI more than females, reason likely being that men are more engaged in activities that predispose them to HI. In our environment commercial motor cycle operators is exclusively a male business, even non- commercial MC users are predominantly males. Also males are mostly involved in other motor vehicle operation and the climbing of heights. ${ }^{18,19}$ Male children are not left out as they are more exploring than the females. This was in keeping with the reports from previous studies on $\mathrm{HI}$ in both developing and developed countries. ${ }^{20 \text {, }}$ 21

Most persons affected in this study are within the youthful age of 21-40 years, which is the period of peak activity and productive age. This corroborates the findings of other authors. ${ }^{20,22}$ Within the paediatric age, age group 0-10 years had the highest frequency; in addition, RTA was the most common etiologic factor followed by falls. This was at variance with studies in other centers wherein fall was most common among children. ${ }^{23}$ 
The major cause of TBI in our study was road traffic accident (RTA) with MC being the highest culprit followed closely by MVA. This finding correlated well with other local studies in our country such as that of Emejulu ${ }^{24}$ et al and Echem $^{25}$ et al. However this was at variance with the situation in the US where fall was reported as the leading aetiological factor ${ }^{26,27}$ This could be as a result of the deplorable nature of our roads coupled with lack of and non-compliance to traffic rules, non-licensing ofvehicle users in our environment. Indeed, the dominance of RTA, precisely from the motorcycle, was a serious indictment on the safety of our roads and conscientiousness of the motorcyclists. Other common causes of $\mathrm{HI}$ observed in this study which have been identified by other studies included assaults, falls, and domestic injuries ${ }^{22,28}$. The commonest form of TBI recorded in our study was the mild HI constituting $61.8 \%$. This was similar to studies by other authors. ${ }^{19}$, ${ }^{22}$ Generally, the outcome of mild HI management is good, although long-term disability could occursometimes. ${ }^{19,29}$

In the present study, the case fatality rate in the AED was $2.6 \%$. This is far lower than the rates reported by Bock-Oruma et al ${ }^{17}(6.8 \%)$, Emejulu et al ${ }^{24}(5.5 \%)$ and Echem et $\mathrm{al}^{25}(22.6 \%)$, This could possibly due to sample size difference, cases severity and effective management strategies in our environment.

The present study had limitations. Being a retrospective study, there was a loss of important information, which could have been relevant. For instance, information on the exact time of the day patient presented at AED and managing outline and outcome in some patients was not specified in the records. This could have helped in advising the governments on effective patrol and traffic regulation implementation on specific periods and also the management of health institutions on staff strength and adequate facilities necessary during these periods for more effective management.

\section{References}

1. Barr RM, Gean AD, Le TH. Craniofacial trauma. In: Brant WE, Helms CA, editors. Fundamentals of Diagnostic Radiology. 4th ed. Philadelphia: Wolters Kluwer Health/Lippincott Williams \& Wilkins. 2012; 49-74.

2. Onwuchekwa RC, Echem RC. An epidemiologic study of traumatic head injuries in the emergency department of a tertiary health institution. J Med Trop 2018; 20:24-9.

3. Bouma GJ, Muizelaar JP, Choi SC, Newlon PG, Young HF. Cerebral circulation and metabolism after severe traumatic brain injury: the elusive role of ischemia. J Neurosurg 1991; 75: 685-93.

4. Bouma GJ, Muizelaar JP, Stringer WA, Choi SC, Fatouros P, Young HF. Ultraearly evaluation of regional cerebral blood flow in severely head-injured patients using xenon-enhanced computerized tomography. J Neurosurg 1992; 77: 360-8

5. Klauber MR, Barrett-Connor E, Marshall LF, Bowers SA. The epidemiology of head injury: a prospective study of an entire community-San Diego County, California, 1978. Am J Epidemiol 1981 113: 500-9.

6. Emejulu JK, Isiguzo CM, Agbasoga CE, Ogbuagu CN. Traumatic brain injury in the accident and emergency department of a tertiary hospital in Nigeria. East Cent Afr J Surg 2010; 15:28-38.

7. Thornhill S, Teasdale GM, Murray GD, McEwen J, Roy CW, Penny KI. Disability in young people and adults one year after head injury: prospective cohort study. $\mathrm{Br}$ Med J 2000; 320: 1631-5.

8. Yates PJ, Williams WH, Harris A, Round A, Jenkins R. An epidemiological study of head injuries in a UK population attending an emergency department, J Neurol Neurosurg Psychiatry, 2006, vol. 77 (pg. 699-701) 
9. Klauber MR, Marshall LF, Luerssen TG, Frankowski R, Tabaddor K, Eisenberg HM. Determinants of head injury mortality: importance of the low risk patient. Neurosurgery 1989; 24: 31-6.

10. Thornhill S, Teasdale GM, Murray GD, McEwen J, Roy CW, Penny KI. Disability in young people and adults one year after head injury: prospective cohort study. $\mathrm{Br}$ Med J 2000; 320: 1631-5.

11. Brain Trauma Foundation, Management and Prognosis of Severe Traumatic Brain Injury, 2000New YorkBrain Trauma Foundation.

12. Hukkelhoven CWPM, Steyerberg EW, Rampen AJJ, et al. Patient age and outcome following severe traumatic brain injury: an analysis of 5600 patients. J Neurosurg 2003; 99: 666-73.

13. Moppett IK. Traumatic brain injury: assessment, resuscitation and early management. BJA: British Journal of Anaesthesia 2007;1: 18-31

14. Chesnut RM, Marshall SB, Piek J, Blunt BA, Klauber MR, Marshall LF. Early and late systemic hypotension as a frequent and fundamental source of cerebral ischemia following severe brain injury in the Traumatic Coma Data Bank. Acta Neurochir Suppl (Wien) 1993; 59:121-5.

15. Hartl R, Gerber LM, Iacono L, Ni Q, Lyons K, Ghajar J. Direct transport within an organized state trauma system reduces mortality in patients with severe traumatic brain injury. J Trauma 2006; 60:1250-6.

16. Lu J, Marmarou A, Choi S, et al. Mortality from traumatic brain injury. Acta Neurochir Suppl 2005; 95: 281-5.

17. Bock-Oruma AA, Odatuwa-Omagbemi DO, Ikubor JE. Pattern of head injury in the emergency department of the Delta state university teaching hospital, Oghara, Nigeria. Br J Med Med Res 2016; 15:1-6.

18. Jasper US, Opara MC, Pyiki EB, Akinrolie O. The epidemiology of hospital-referred head injury in Northern Nigeria. J Sci Res Rep 2014; 3:2055-64.

19. Boniface R, Lugazia ER, Ntungi AM, Kiloloma O. Management and outcome of traumatic brain injury patients at Muhimbili Orthopaedic Institute Dar es Salaam, Tanzania. Pan Afr Med J 2017; 26:140.

20. Thurman D, Guerrero J. Trends in hospitalization associated with traumatic brain injury. JAMA 1999; 282:954-7.

21. Yates PJ, Williams WH, Harris A, Round A, Jenkins R. An epidemiological study of head injuries in a UK population attending an emergency department. J Neurol Neurosurg Psychiatry 2006; 77:699-701.

22. Emejulu JK, Isiguzo CM, Agbasoga CE, Ogbuagu CN. Traumatic brain injury in the accident and emergency department of a tertiary hospital in Nigeria. East Cent Afr J Surg 2010; 15:28-38.

23. Quayle KS, Powell EC, Mahajan P, Hoyle JD Jr, Nadel FM, Badawy MK et al. Epidemiology of blunt head trauma in children in US emergency departments. N Engl J Med 2014; 371:1945-7.

24. Emejulu J.K.C., Isiguzo CM, Agbasoga $\mathrm{CE}$, Ogbuagu CN. Traumatic Brain Injury in the Accident and Emergency Department of a Tertiary Hospital in Nigeria. East and Central African Journal of Surgery 2010;15: 28-38.

25. Onwuchekwa RC, Echem RC. An epidemiologic study of traumatic head injuries in the emergency department of a tertiary health institution. J Med Trop 2018;20:24-9

26. Thurman D, Janet G (1999); Trends in Hospitalization Associated with Traumatic Brain Injury, Journal of American Medical Association; 282:954 - 957.

27. CDC-NCPIC (2008 March), Traumatic Brain Injury; http://www.cdc.gov/ncipc/ factsheets /tbi.htm 
28. Shivaji T, Lee A, Dougall N, McMillan T, Stark C. The epidemiology of hospital treated traumatic brain injury in Scotland. BMC Neurol 2014;14:2

29. Palacios EM, Yuh EL, Chang YS, Yue JK, Schnyer DM, Okonkwo DO et al. Restingstate functional connectivity alterations associated with six-month outcomes in mild traumatic brain injury. J Neurotrauma 2017;34:1546-57. 